\title{
PROJETO CARONA SOLIDÁRIA NA UFPR
}

CARPOOLING PROJECT IN UFPR

Ricardo Mendes Junior, Dr. ${ }^{1}$

Rafael Fusco ${ }^{2}$

Este artigo relata as iniciativas de carona solidária desenvolvidas na UFPR nos últimos anos. Estas iniciativas envolveram professores, estudantes, os centros acadêmicos do Setor de Tecnologia (C7) e o Programa Ciclovida. Apresentamse um histórico destas ações, seus objetivos e formas de organização e realização. Verificou-se que as iniciativas são viáveis e podem ser amadurecidas e que a comunidade aceitou bem a ideia da carona solidária. Podemos concluir que existe sim uma demanda urgente em resolver o sistema de mobilidade na cidade e a Universidade Federal deve ser um exemplo de soluções inovadoras e uma incubadora de projetos desenvolvidos pela comunidade.

Palavras-chave: carona solidária; mobilidade; bicicleta.

This paper reports on the initiatives developed in carpooling UFPR in recent years. These initiatives involved teachers, students, the academic centers of the Technology Sector (C7) and Ciclovida Program. We present a history of these actions, goals and ways of organizing and executing. It was found that the initiatives are feasible and can be matured and that the community has accepted the idea of carpooling very well. We can conclude that there is an urgent demand to resolve the mobility system in the city and the Federal University should be an example of innovative solutions and an incubator of projects which would be developed by the community.

Keywords: carpooling; mobility; bicycle.

\section{Introdução}

Nos últimos anos o trânsito nos grandes centros urbanos tem piorado consideravelmente, com engarrafamentos cada vez maiores, resultando no aumento dos tempos de deslocamentos tanto no transporte individual (automóvel) quanto coletivo, e acarretando uma menor qualidade de vida das pessoas. A falta de investimentos em infraestrutura de transporte e o aumento nas vendas de automóveis podem ser as causas principais destes problemas.

\footnotetext{
${ }^{1}$ Graduado em Engenharia Civil (UFPR), Mestre em Engenharia Civil (UFRGS) e Doutor em Engenharia de Produção (UFSC). Professor do Departamento de Engenharia de Produção, UFPR - mendesjr@ufpr.br

${ }^{2}$ Acadêmico de Arquitetura e Urbanismo, UFPR.
} 
A frota veicular brasileira cresceu de $29.722 .950 \mathrm{em} 2000$ para $64.817 .974 \mathrm{em}$ 2010 (Denatran, 2010), com um aumento de 100,8\%. No mesmo período a população cresceu de 169.799.710 (IBGE, 2010a) para 190.755.799 (IBGE, 2010b), com um aumento de 12,3\%. De dezembro de 2010 até setembro de 2012 foram emplacados mais 9.871 .732 veículos.

A concentração da população nos grandes centros urbanos tem gerado os problemas complexos de infraestrutura e mobilidade que temos. Boa parte destes problemas está relacionada ao excesso de automóveis em circulação. Aqui também se colocam problemas de stress urbano, poluição ambiental, investimentos necessários na infraestrutura exclusivamente para atender automóveis em detrimento dos pedestres. Todos estes problemas tendem a resultar numa vida menos saudável.

O impacto do transporte sobre o ambiente também tem sido bastante discutido. A emissão de gases na atmosfera é responsável, de acordo com muitos pesquisadores, por boa parte das alterações na atmosfera terrestre e contribuindo para aquecimento global. Os quais, por sua vez, acreditam muitos pesquisadores, são responsáveis pelas alterações ambientais e climáticas por que a Terra está passando.

Praticamente todas as recomendações de colaboração com um meio ambiente mais saudável incluem o uso mais comedido do automóvel, sua substituição pela bicicleta, o uso do transporte público, ou a carona solidária. $O$ que estamos chamando no Brasil de carona solidária é conhecido em outros países como car pooling. As iniciativas de carona solidária no Brasil ainda são muito reduzidas. $O$ car pooling não deve ser confundido com o car sharing, que é o uso compartilhado de um automóvel na forma de um aluguel por um período por um curto período de tempo, ou à hora. Os serviços de car sharing já são em grande número de diversos países e sua facilidade de aluguel tira vantagem do uso da tecnologia, o aluguel e a liberação do automóvel podem ser feito pela internet, telefone ou aplicativo em celular. Os automóveis podem ser da frota da empresa ou dos próprios particulares. Em São Paulo já há uma empresa que explora este serviço.

As iniciativas de carona solidária de conhecimento do público em geral que já existem no Brasil iniciaram com o desenvolvimento de websites para facilitar a carona em algumas universidades, como por exemplo, o 
www.unicaronas.com.br desenvolvido por dois estudantes da Unicamp em 2007. Nos anos seguintes vários outros serviços similares surgiram na web, sejam de forma gratuita ou pagas. Os serviços pagos têm como foco principalmente as grandes empresas com grande número de funcionários que vão ao trabalho de carro. Nestes casos as empresas procuram incentivar as caronas com algum benefício.

A aceitação da carona solidária no Brasil ainda enfrenta uma barreira cultural, por conta da relação que o proprietário tem com o seu carro. Schmitt (2006) apud Ferreira et al (2011) apresenta um estudo dos fatores que influenciam a adoção da carona que mostra que estas barreiras variam com a idade e a renda. Pessoas de menor renda e menor idade tem maior aceitação. Outras questões como o trajeto realizado pelo motorista e a sua flexibilidade de horário também influenciam nesta aceitação. Desta constatação surgiu a ideia de experimentar a carona solidária na comunidade acadêmica.

\section{O projeto e seu início}

Com o objetivo de mobilizar a comunidade acadêmica, a partir dos alunos que compõem o maior universo foi idealizado em 2009 o projeto Carona Solidária. O Carona Solidária é um projeto do Programa Ciclovida da UFPR. Os principais objetivos do projeto são uma mobilidade urbana mais sustentável, redução de carros estacionados nos campi da UFPR e, por consequência uma menor circulação de carros e a redução nas emissões dos gases efeito estufa.

A primeira ação do projeto foi organizada pelo Centro Acadêmico de Engenharia de Produção, com apoio de alunos voluntários, no dia 19 de novembro de 2010. A figura 1 apresenta o flyer desta ação. Com divulgação em sala de aula formou-se um grupo de 20 alunos voluntários, que utilizam o automóvel para vir ao campus Centro Politécnico. Com os dados de origem e percurso destes alunos foi feito um compartilhamento de suas rotas de casa até o campus, e proposto que 8 alunos iriam compartilhar os carros no dia da ação. A ação foi bem sucedida e o objetivo seguinte seria aumentar o número de participantes. 


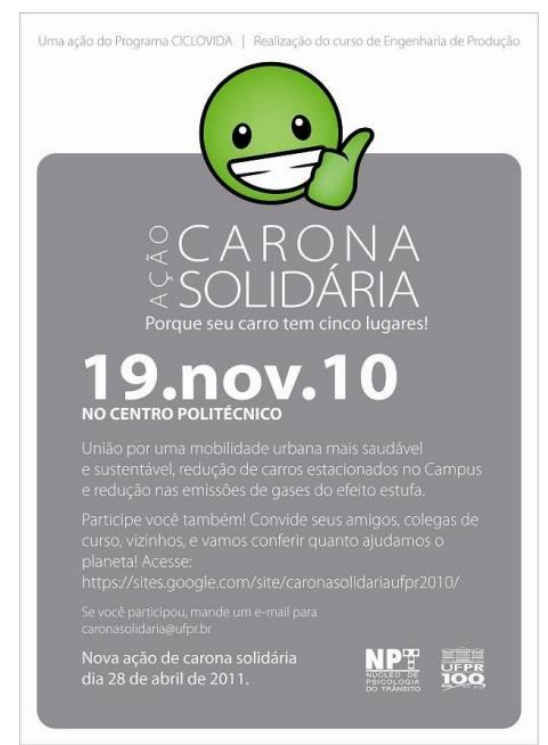

Figura 1 - Material de divulgação da primeira ação.

FONTE: Projeto Carona Solidária (2010)

Para tanto uma meta do projeto foi o desenvolvimento de um sistema de computação na web para que os motoristas cadastrem seus percursos e possam se comunicar entre si para combinar as caronas. O desenvolvimento deste sistema foi iniciado em 2011 com a colaboração de um aluno do Curso de pós-graduação em Desenvolvimento de Software para Mercados Internacionais (CEDSMI), do Departamento de Ciência e Gestão da Informação (DECIGl) e ainda não concluído.

Em Abril de 2010 foi realizado em Curitiba o 29ํㅡㄹ Encontro da Regional Sul de Estudantes de Arquitetura e Urbanismo, que tinha como um dos principais eixos de discussão a Mobilidade Urbana. Com a participação de cerca de 2000 estudantes, foram realizadas palestras, visitas guiadas, oficinas, mesas e debates sobre o assunto, com a participação de diversos agentes da sociedade civil, do estado, técnicos e acadêmicos.

De volta a Universidade, no dia 17 de Maio de 2010 o estudante Rafael Fusco apresentou ao C7 - Conselho dos Estudantes do Setor de Tecnologia a ideia de um projeto de caronas, expondo a problemática já conhecida do atual sistema de transporte e de mobilidade. Nesse momento foi idealizado um modelo dinâmico, diferenciado do que já se havia estudado em outras universidades. 
O projeto foi apreciado pelos membros do Conselho e seria amadurecido durante os meses seguintes junto aos Centros Acadêmicos e Administração da UFPR.

Em paralelo, houve a ação organizada pelo Ciclovida que culminou no projeto realizado pelo Centro Acadêmico de Engenharia de Produção. Como resultado, formou-se um grupo de discussão e o estudante Lucas Panga Catanho fez a ponte entre o Programa Ciclovida e o C7, através dos 8 Centros Acadêmicos.

Em Maio de 2011 se estabeleceu a metodologia de trabalho e o calendário para uma Semana Piloto do Carona Solidária, bem como o produto esperado e os indicativos para analisar os resultados.

\section{Semana Piloto em 2011}

No início do ano iniciou-se o planejamento de uma nova ação, agora de uma semana de duração, nos dias 13 a 17 de junho. Considerando que a motivação das pessoas para aceitar a carona é uma das principais barreiras para a aceitabilidade da carona, a proposta desta nova ação foi envolver toda a comunidade, sejam pessoas que usem o carro para vir ao campus ou não. Assim a chamada para a ação abordou o problema do excesso de carros e também o problema das grandes filas nos pontos de ônibus, como mostra na figura um dos materiais utilizados na ação.

O objetivo da Semana foi divulgar o projeto e propagar a ideia de que o hábito da carona é um solução simples, de solidariedade, que pode contribuir não só com os problemas ambientais e de trânsito, mas também diminuir seu tempo de viagem ou custo, dependendo da parte envolvida. Além disso, promove a integração entre estudantes e servidores de áreas diversas, esteritando os laços criados pela instituição UFPR e consolidando uma comunidade capaz de atuar em prol de si mesma.

No final, esperava-se analisar o comportamento dos participantes da Semana e projetar um sistema físico e virtual que atendesse às necessidades e condicionantes do campus Centro Politécnico, e superasse as dificuldades que viessem a aparecer. 
Filas gigantescas. Lotação, no ônibus e no estacionamento. Poluição. Tempo perdido.

Faça parte do Programa Carona Solidária e ajude a mudar esta realidade. Além de colaborar com um colega, você ainda pode descobrir alguém para dividir os custos e ajudar o meio ambiente.

Na Semana Piloto, de 13 a 17 de junho, um estacionamento inteirinho será reservado para o projeto. Procure o Ponto do Carona em frente ao Bloco de Ciências da Terra, próximo ao sinaleiro do Centro Politécnico. Lá, equipes treinadas farão o cadastro de informações do Carona e Caroneiro e ajudarão na integração entre eles.

\section{QAfls QMIFOS //}

\section{Como Participar}

Preencha seu cadastro com nossa equipe e informe se é Carona ou Caroneiro.

\section{Ponto do Carona}

Estacionamento Ciências da Terra (em frente ao sinaleiro do Centro Politécnico)

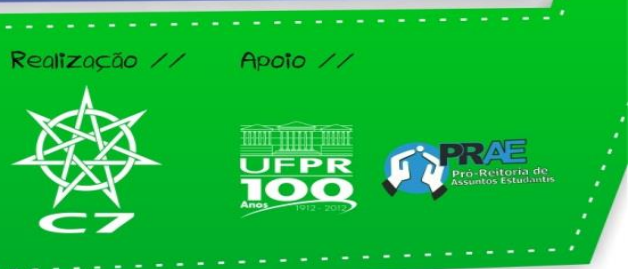

Figura 2 - Material de divulgação da ação piloto.

FONTE: Projeto Carona Solidária (2011)

A estrutura organizada para esta ação piloto incluiu:

- Área de estacionamento para 40 carros dotada com uma tenda de 10x10m - Ponto de Carona

- Monitores uniformizados e equipados com walk talk

- Banners, cartazes e flyers de divulgação

- Fichas de cadastro e feedback a serem preenchidas pelos usuários

- Adesivos para identificação dos carros

- Divulgação em meios de comunicação da UFPR e das grandes mídias de Curitiba

- Mapa com as principais rotas de deslocamento do campus para os bairros da cidade (ver figura 3) 


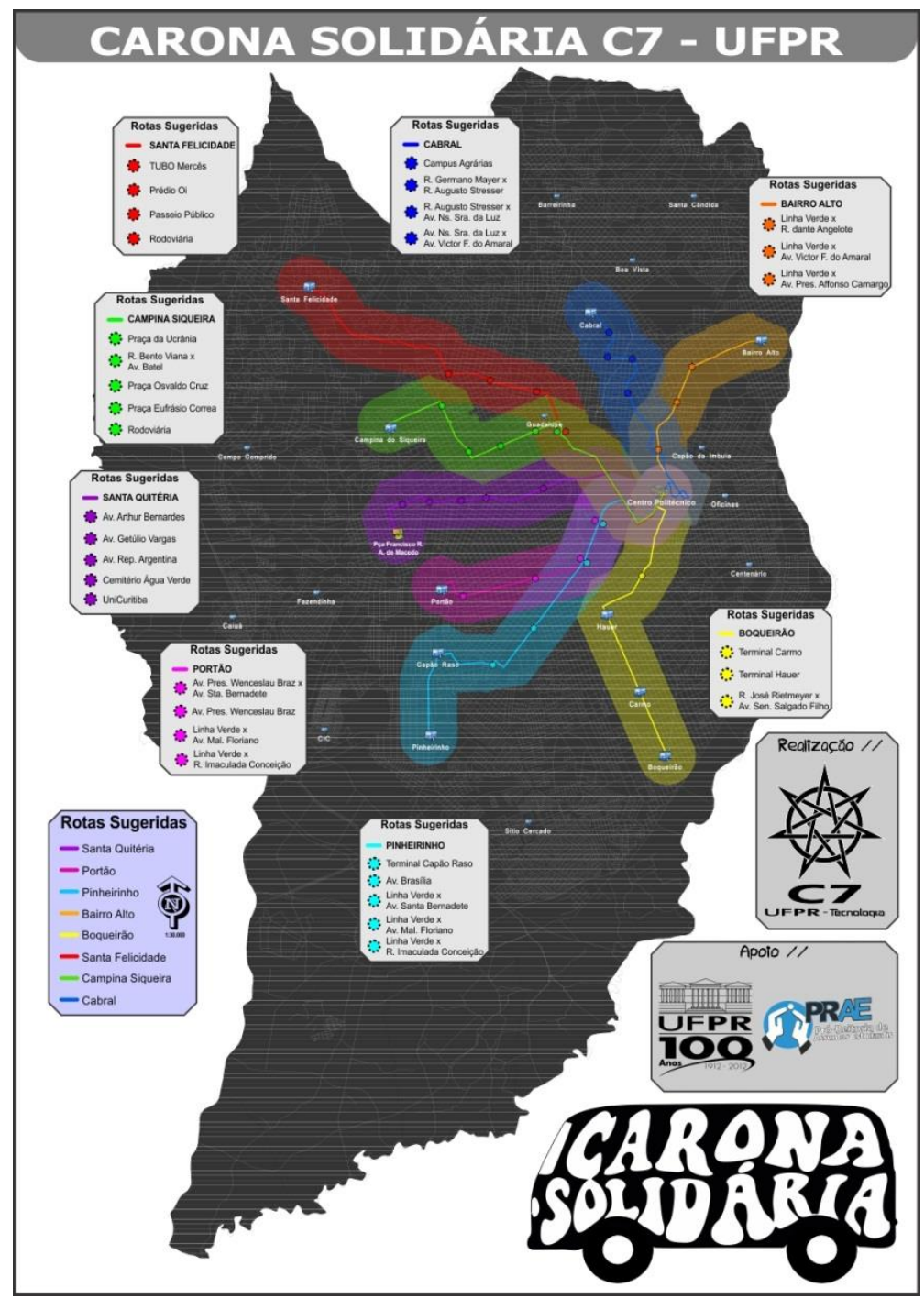

Figura 3 - Mapa com as principais rotas de deslocamento FONTE: Projeto Carona Solidária (2011)

A atuação dos apoios consistiu na divulgação do projeto e na organização de caronas no Ponto da Carona, fazendo a conexão entre os que esperavam e os que saiam de carro. No encontro entre as duas partes, foi preenchido o cadastro e realizado um pequeno feedback sobre o projeto e o hábito da carona.

O resultado foi mais satisfatório que o esperado, atingindo cerca de 1900 pessoas entre motoristas e caroneiros, e com uma aceitação quase unânime a prática da carona, desde que devidamente organizada e com garantias de segurança às partes. 
A repercurssão se deu em toda a UFPR, e a partir daí se planteou a implementação do projeto em todos os campi, e a criação de uma plataforma virtual que atendesse às demandas e tivesse praticidade de uso.

As ações subsequentes, programadas para o segundo semestre de 2011, foram afetadas pela greve dos servidores daquele ano, tomando tempo e energia dos organizadores do Carona Solidária, que também eram representantes do movimento estudantil.

\section{Continuidade em 2012}

Para o ano de 2012 as ações programadas teriam três iniciativas novas:

a) O uso de um sistema de informação para a busca de caronas: o sistema ainda está em desenvolvimento

b) Estender a ação para os campi Agrárias e Botânico;

c) Pontos fixos de carona: estes pontos foram executados no Centro Politécnico e identificados com pintura no chão (ver figura 4)

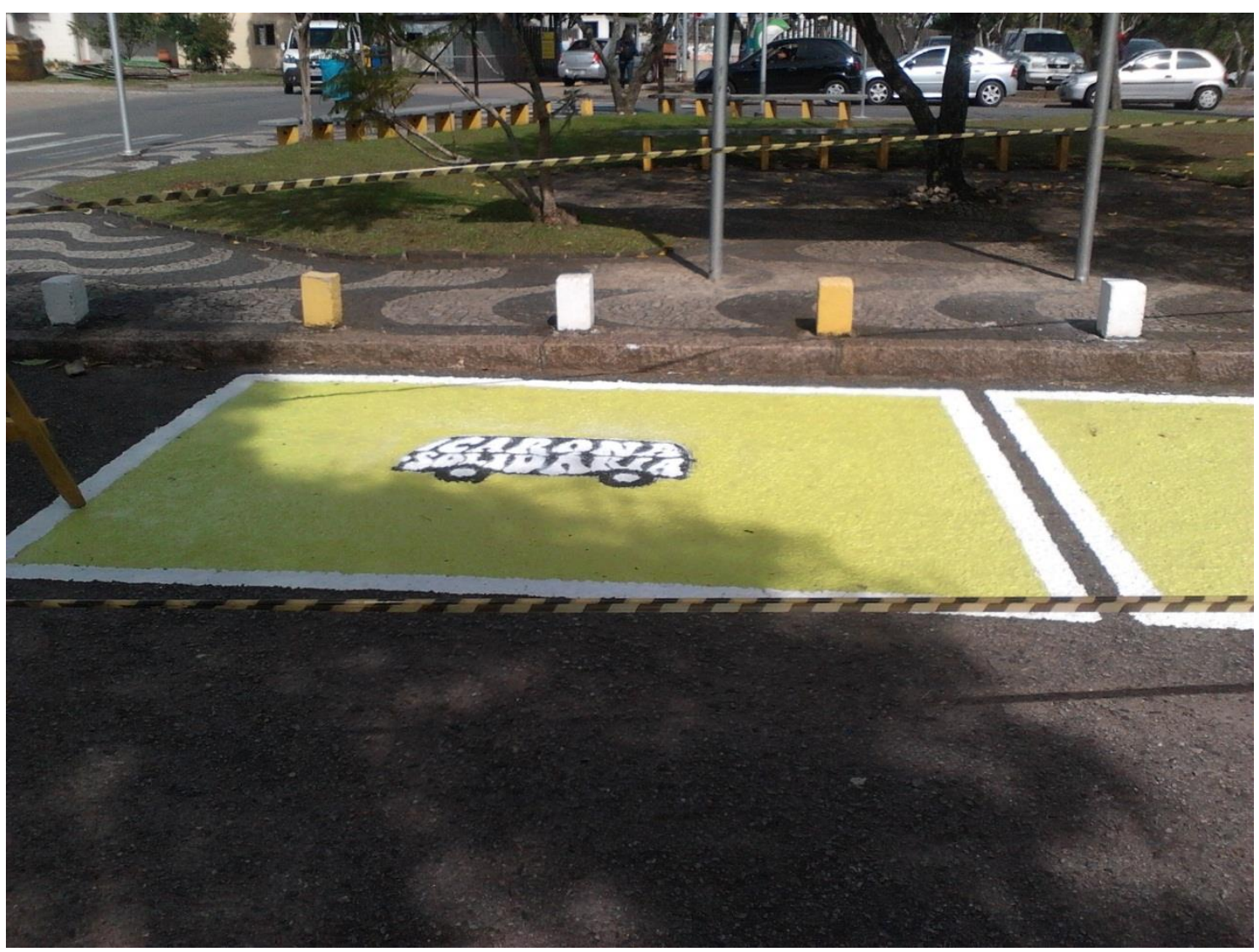

Figura 4 - Ponto fixo de carona solidária FONTE: Projeto Carona Solidária (2012) 


\section{Considerações Finais}

O artigo apresentou as iniciativas de carona solidária que vêm sendo conduzida nos últimos por um grupo de professores, estudantes, centros acadêmicos do Setor de Tecnologia (C7) e o Programa Ciclovida, com o objetivo de realizar algo concreto para a redução do número de automóveis nos campi da UFPR e sensibilizar a comunidade acadêmica que a carona solidária é uma alternativa para muitas situações do dia a dia das pessoas em relação à mobilidade. A aceitação que o projeto teve junto à comunidade, que foi grande, mostrou que as ações devem continuar. Verificou-se ainda que as iniciativas são viáveis e podem ser amadurecidas.

Podemos concluir que existe sim uma demanda urgente em resolver o sistema de mobilidade na cidade e a Universidade Federal deve ser um exemplo de soluções inovadoras e uma incubadora de projetos desenvolvidos pela comunidade.

Temos em nossa comunidade um potencial maior que qualquer outra instituição, porém continuamos importando as más práticas externas ao invés de propor modelos simples que garantam melhor qualidade e respeito mútuo no nosso dia a dia.

Para isso, é imprescindível o apoio à pesquisa e extensão e à organizações estudantis, bem como o suporte a construção de projetos independentes.

\section{REFERÊNCIAS}

DENATRAN. Frota nacional brasileira - Frota 2010. Disponível em http://www.denatran.gov.br/frota.htm Acessado em 16/11/2012. 2010

FERREIRA, Amanda Fernandes, RIBEIRO, Renato Guimarães, e BARBOSA, Heloisa. "Aceitabilidade da carona programada como forma de gerenciamento da demanda por estacionamento em uma instituição de ensino." XXV ANPET, Belo Horizonte (2011).

IBGE, Censo Demográfico 2000 - Resultados do Universo. Disponível em http://www.ibge.gov.br/home/estatistica/populacao/censo2000/tabelabrasil111.s htm Acessado em 16/11/2012. 2010a 
IBGE, Resultados do Universo do Censo de 2010. Disponível em ftp://ftp.ibge.gov.br/Censos/Censo_Demografico_2010/Resultados_do_Univers o/tabelas_pdf/tab1.pdf Acessado em 16/11/2012. 2010b 